\title{
Effects of COVID-19 Fear on Society's Quality of Life
}

\author{
Nur Demirbas $^{1}$ (D) Ruhusen Kutlu ${ }^{1}$ (D)
}

Accepted: 20 May 2021 / Published online: 15 September 2021

(c) The Author(s), under exclusive licence to Springer Science+Business Media, LLC, part of Springer Nature 2021

\begin{abstract}
The COVID-19 pandemic is an important factor affecting the health of people worldwide, as well as a source of fear, stress, and anxiety. The aim of this study was to determine the level of fear caused by the COVID-19 pandemic in Turkish society and evaluate its effects on quality of life. The sociodemographic information form, COVID-19 Fear Scale (FCV-19S), and WHOQOL-BREF Quality of Life Scale were applied to the participants. A total of 705 people, who were accessed via the internet, responded willingly to the study, which was planned as a cross-sectional analytical study. The mean FCV-19S score was $17.4 \pm 5.9$ (7-32) points. Fear points were higher among females than males $(p<0.001)$, and among single individuals than among those who were married $(p=0.049)$. Fear scores were low for tradesmen, those with low educational status, and those with high income levels $(p<0.001)$. According to the WHOQOL-BREF Scale, the FCV19S of those with very good quality of life was low $(p=0.042)$, and the FCV-19S of those who were not satisfied with life was high $(p<0.001)$. Statistically, a weak negative correlation was detected between the fear scores, and physical health and psychological health $(r=-0.190$, $r=-0.198, p<0.001)$. Fear level varies according to gender, education, and income level, regardless of age. As fear increases, quality of life decreases, and physical and psychological health were negatively affected. The authors believed that the outcome of the study would help inform the public about COVID-19, as well as cope with the psychological effects and fears of COVID-19.
\end{abstract}

Keywords COVID-19 $\cdot$ Fear $\cdot$ Quality of life $\cdot$ Mental health

Pandemic is a general name given to epidemics that spread and are effective over a wide area in more than one country or continent. During the last days of 2019, cases of pneumonia of unknown etiology were reported from the city of Wuhan, Hubei Province, China. The causative agent was first isolated on January 7, 2020 and identified as a new type of coronavirus (Zhang \& Ma, 2020). The new type of coronavirus outbreak was declared by

Nur Demirbas

ndemirbas76@hotmail.com

Ruhusen Kutlu

ruhuse@yahoo.com

1 Department of Family Medicine, Meram Medical Faculty, Necmettin Erbakan University, 42080 Konya, Turkey 
the World Health Organization (WHO) as a controllable pandemic on March 11, 2020 (World Health Organization, 2020). The first confirmed COVID-19 case in Turkey was announced on March 10, 2020, with the first death related to COVID-19 on March 17, 2020. The Turkish government took the necessary measures to prevent the spread of the coronavirus as soon as possible. Use of masks became mandatory, containment measures, such as social distancing, travel bans to high risk countries, and quarantine for all citizens returning from these countries, and the locking down of gyms, shopping malls, cinemas, and entertainment venues were taken, and all schools and universities were closed on March 16, 2020 (TC. Ministry of Health, 2020).

Everyone was adversely affected biologically, psychologically, and socially due to the increasing number of cases. Scientists emphasized that in addition to the diagnostic and therapeutic aspects of treating COVID-19, the impact of the crisis on the mental health of individuals was also important (Ozamiz-Etxebarria et al., 2020). Fear and panic about COVID-19 can lead to psychological health issues, such as the exclusion of positively tested patients, survivors, their families and other individuals associated with the disease from society, and adjustment disorder and depression (Harper et al., 2020). During disease outbreaks, news of the first deaths, increases in the number of new cases, and media misinformation can increase people's fears, frustration, despair, and anxiety. In addition, uninfected individuals reported that they were afraid to be in contact with people infected with COVID-19 (Ahorsu et al., 2020). Fear of catching the COVID-19 virus can cause irrational and ambiguous thoughts in individuals and adversely affect their quality of life (Pakpour \& Griffiths, 2020). Fear of COVID-19 causes delays in accessing healthcare. In order to mitigate and control the negative consequences of COVID-19, early detection and effective combat of psychological problems such as fear and anxiety are very important. Today, while medicine is progressing, it is aimed not only to eliminate diseases, but also to improve the quality of life of people. Therefore, increasing efforts are ongoing to measure well-being and quality of life. The WHO developed a comprehensive Quality of Life Scale (World Health Organization Quality of Life-WHOQOL) to measure and evaluate the quality of life ("The World Health Organization Quality of Life Assessment (WHOQOL)", 1998).

While people are afraid for both themselves and their relatives being sick and dying, they also experience the material and moral difficulties brought on by the pandemic (Shultz et al., 2016). In addition to the fear of illness and death, the lockdown for adults at the age of 65 and above, closure of many workplaces, social distancing, and other pandemic rules increased the depression and anxiety levels of individuals (Shigemura et al., 2020). These developing negative emotions and psychological problems may change the quality of life of individuals. In this respect, this study aimed to evaluate the level of fear experienced by the Turkish community during the COVID-19 epidemic, its change with sociodemographic characteristics, and its effects on physical, spiritual, and social quality of life.

\section{Method}

\section{Participants}

In this study, which was planned as a cross-sectional analytical study, people were reached through the internet, social media, and communication networks using the snowball sampling method. Turkish people living in different provinces and over the age of 18 years 
were used in this study. It was aimed to include least 377 people with a 5\% margin of error and $95 \%$ confidence interval, and it was planned to include at least 420 people due to the possibility of missing questionnaire answers and refusal to participate in the study.

\section{Ethical Permit for the Study}

Ethical permission for the research was taken prior to the study from Necmettin Erbakan University Meram Faculty of Medicine, Department of Pharmaceuticals and Non-Medical Research Ethics Committee (number 2020/2673). The study protocol was approved by the Turkish Ministry of Health, General Directorate of Health Services (Approval Date/ Number: 2020-06-08T14_08_12). The participants were informed about the study, and their written consent was obtained according to the principles of the Helsinki Declaration.

\section{Study Design and Procedure}

After receiving the approval of the ethics committee for the study, the study was announced via different social networks (e.g., Facebook, Instagram, Whatsapp) over a month period, and the objective of the study was explained, and the volunteers were given the link (https:// forms.gle/zmyejng778gkxsxz6) and asked to fill out the questionnaire. The questionnaire form created using Google Forms was anonymous and based on voluntary consent. There was no remuneration for participating in the online survey. The online questionnaire was prepared in Turkish to be applied only to Turkish citizens as stated in the recruitment criteria. In addition, attention was paid to sending the online questionnaire only to Turkish citizens.

\section{Data Collection Tools}

The first part of the three-part questionnaire contained questions prepared for determining the sociodemographic characteristics of the participants, questions on their daily lives, and about the COVID-19 pandemic. In the second part, the fear of COVID-19 was discussed, and in the third part, the WHOQOL-BREF Quality of Life Scale was applied.

\section{Sociodemographic Information Form}

The questionnaire, which contains information about the individual, was prepared by the researchers by scanning the relevant literature. It consists of 7 questions about age, gender, marital status, education level, and the COVID-19 pandemic.

\section{COVID-19 Fear Scale}

The scale developed by Ahorsu et al. (2020), of which the validity study in Turkish was conducted by Bakioğlu et al. (2020) and Satici et al. (2020), consists of 7 single-dimension items and is scored with a 5-point Likert scale. The Cronbach alpha reliability coefficient was determined as 0.820 . As the scores obtained from the scale increase, the level of fear increases (Ahorsu et al., 2020; Bakioğlu et al., 2020; Satici et al., 2020). In the presented study, the Cronbach alpha reliability coefficient of the scale was determined as 0.874 . 


\section{WHOQOL-BREF Quality of Life Scale}

This health-related quality of life scale was developed by the WHO ("The World Health Organization Quality of Life Assessment (WHOQOL)", 1998), and the Turkish validity and reliability study was conducted by Eser et al. (Eser et al., 1999). This scale covers 26 questions and 4 fields, which include physical (7 items), spiritual (6 items), social (3 items), and environment ( 8 items) fields. There are questions about the ability to perform daily chores, dependence on drugs and treatment, mobility, pain, sleep and rest, and ability to work in the physical field. The spiritual field contains questions regarding positive and negative emotions, self-esteem, appearance, personal beliefs, and concentration, while those in the social field consist of questions about relationships with other people, social support, and sexual life. In the environment field, there are questions about the home environment, physical security and safety, financial resources, health services, accessibility, making use of spare time, physical environment, and transportation. Field scores can be calculated separately between 4-20 and 0-100. It is demonstrated that the quality of life increases as the field scores increase.

\section{Statistical Analysis}

In the study, all data obtained through Google Forms distributed through the internet and social media networks (https://forms.gle/x77bb5cqxqvedacs5) were evaluated using IBM SPSS Statistics 20.0 (Armonk, NY, USA). Average and standard deviation values of the numerical data were calculated. Normal distribution and skewness and kurtosis value was evaluated using the Kolmogorov-Smirnov test and Shapiro-Wilk test. The categorical and numerical data in non-parametric distribution were compared with appropriate statistical analyses such as the Kruskal-Wallis test in groups of two and the Mann-Whitney $U$ test in groups of three and more. $p<0.05$ was considered statistically significant. Reliability scores of each scale were calculated using the Cronbach alpha. Pearson correlation analysis was used to determine the correlation between the fear and quality of life scores. Multivariate linear regression analysis was conducted to determine the risk factors of COVID-19 fear.

\section{Results}

The average age of 705 people who participated in the study was $44.2 \pm 13.5$ (18-71) years. Of the participants, $51.6 \%(n=364)$ were female, $71.9 \%(n=507)$ were married, $38.9 \%(n=274)$ were officer, $23.7 \%(n=167)$ were tradesman, and $61.7 \%(n=435)$ were university graduated. The mean FCV-19S score of the COVID-19 fear scale was $17.4 \pm 5.9$ (7-32) points. When the COVID-19 fear and sociodemographic characteristics of the participants were compared, the fear scores of females were higher than the males and those of the single individuals were higher than those who were married, and this difference was statistically significant $(p<0.001$ and $p=0.049$, respectively). The fear scores of the tradesman, primary school-educated people, and those with expenses higher than their income were significantly lower than the housewives and officers 
Table 1 Comparison of sociodemographic characteristics with COVID-19 fear score

\begin{tabular}{|c|c|c|c|c|c|}
\hline & & & COVID-19 f & score & \\
\hline & & $n(\%)$ & Mean \pm SD & $Z / F$ & $p$ \\
\hline Gender & Female & $364(51.6)$ & $18.8 \pm 5.9$ & $6.568 *$ & $<0.001$ \\
\hline & Men & $341(48.4)$ & $15.9 \pm 5.5$ & & \\
\hline Marital status & Married & $507(71.9)$ & $17.1 \pm 6.0$ & $-1.968 *$ & 0.049 \\
\hline & Single & $198(28.1)$ & $18.1 \pm 5.5$ & & \\
\hline Occupation & Student ${ }^{\mathrm{a}}$ & $69(9.8)$ & $16.8 \pm 4.5$ & $6.230 * *$ & $<0.001^{\text {ce }}$ \\
\hline & Retired $^{\mathrm{b}}$ & $94(13.3)$ & $17.7 \pm 6.0$ & & $0.006^{\mathrm{de}}$ \\
\hline & Housewife $^{c}$ & $101(14.3)$ & $19.2 \pm 6.6$ & & \\
\hline & Officer $^{\mathrm{d}}$ & $274(38.9)$ & $17.7 \pm 5.7$ & & \\
\hline & Tradesman $^{\mathrm{e}}$ & $167(23.7)$ & $15.8 \pm 5.8$ & & \\
\hline Education & Elementary school $^{\mathrm{a}}$ & $66(9.4)$ & $15.1 \pm 6.4$ & $8.024 * *$ & $<0.001^{\text {ab }}$ \\
\hline & Secondary school $^{\mathrm{b}}$ & $108(15.3)$ & $19.1 \pm 5.1$ & & $\mathbf{0 . 0 0 3}^{\text {ac }}$ \\
\hline & High school $^{\mathrm{c}}$ & $96(13.6)$ & $18.3 \pm 6.2$ & & \\
\hline & University $^{\mathrm{d}}$ & $435(61.7)$ & $17.1 \pm 5.8$ & & \\
\hline Financial status & Less than income & $222(31.5)$ & $17.9 \pm 6.2$ & $6.909 * *$ & $<0.001$ \\
\hline & Income equal to expense & $296(42.0)$ & $17.8 \pm 5.6$ & & \\
\hline & More than income & $187(26.5)$ & $16.0 \pm 5.8$ & & \\
\hline
\end{tabular}

*Mann-Whitney $U$ test

${ }^{* * *}$ Kruskal-Wallis test

$(19.2 \pm 6.6)$, second and high school educated people $(19.1 \pm 5.1)$, and low-income individuals $(17.9 \pm 6.2)(p<0.001)$ (Table 1$)$.

In this study, the Cronbach alpha reliability scores of FCV-19S were 0.824 and WHOQOLBREF were 0.723 .

The COVID-19 fear score averages of those with quality of life-very good (16.0 \pm 7.3$)$ were statistically significantly lower than those of the neither good nor bad $(18.1 \pm 5.9)$ $(p=0.042)$. The mean score for fear of COVID-19 among those with satisfaction-very satisfied life $(14.2 \pm 5.2)$ was significantly lower than those of the not satisfied (19.1 \pm 7.2 ; $p<0.001$ ) (Table 2). According to the correlation analysis, there was a weak significantly negative correlation between the fear of COVID-19 and physical health $(r=-0.190, p<0.001)$. Again, there was a weak significantly negative correlation between the fear of COVID-19 and psychological health $(r=-0.198, p<0.001)$ (Table 3).

Multivariate linear regression analysis was conducted to determine the risk factors of COVID-19 fear. According to the results of the multi-linear regression analysis, only the psychological health field score was found to have a negative and statistically significant effect on COVID-19 fear $(\beta=-0.198, p<0.001)$ Each increase of one unit in the physical health field score and psychological health field score resulted in a 19.0\% reduction in the COVID-19 fear. 
Table 2 Comparison of quality of life and life satisfaction with COVID-19 fear

\begin{tabular}{llll}
\hline \multicolumn{4}{c}{ COVID-19 fear score } \\
\cline { 2 - 3 } & Mean \pm SD & $F$ & $p^{*}$ \\
\hline General health and quality of life & & & \\
$\quad$ Very bad & $16.6 \pm 5.2$ & 2.484 & $\mathbf{0 . 0 4 2}$ \\
A little bad & $17.0 \pm 7.1$ & & \\
Neither good nor bad & $18.1 \pm 5.9$ & & \\
Pretty good & $16.7 \pm 5.2$ & & \\
Very good & $16.0 \pm 7.3$ & & \\
General health and life satisfaction & & \\
Not satisfied & $19.1 \pm 7.2$ & 7.413 & \\
Very little dissatisfaction & $19.1 \pm 5.9$ & & \\
Neither satisfied nor not & $17.4 \pm 6.0$ & & \\
Pretty satisfied & $17.3 \pm 5.5$ & & \\
Very satisfied & $14.2 \pm 5.2$ & & \\
\hline
\end{tabular}

${ }^{*}$ Kruskal-Wallis test

Table 3 Correlation between age, COVID-19 fear, and WHOQOL-BREF subscales

\begin{tabular}{lllllll}
\hline & & Age & 1 & 2 & 3 & 4 \\
\hline 1. COVID-19 fear score & $r$ & -0.027 & & & & \\
2. Physical health area & $r$ & -0.041 & $-0.190^{* *}$ & & & \\
3. Psychological health area & $r$ & 0.083 & $-0.198^{* *}$ & $0.571^{* *}$ & & \\
4. Social relations area & $r$ & 0.000 & -0.028 & $0.418^{* *}$ & $0.349^{* *}$ & $0.395^{* *}$ \\
5. Environmental area-TR & $r$ & $0.187^{* *}$ & -0.069 & $0.499^{* *}$ & $0.536^{* *}$ & 0.06 \\
\hline
\end{tabular}

${ }^{* *}$ Correlation is significant at the 0.01 level (2-tailed)

\section{Discussion}

Fear is an emotional response to serious life-affecting threats such as COVID-19 (Bavel et al., 2020). In this study, conducted to determine the level of fear created by the COVID19 pandemic in Turkish society, it was observed that the level of fear varied depending on gender, marital status, occupation, educational level, and economic status. Physical and psychological health was adversely affected by the increase in the level of fear.

In a pandemic, fear increases anxiety and stress levels in healthy individuals and intensifies the symptoms of those with pre-existing psychiatric disorders (Ornell et al., 2020). The number of people whose mental health is affected by the pandemic tends to be more than the number of people affected by the infection. (Shigemura et al., 2020). The high level of fear associated with COVID-19 can also cause irrational and ambiguous thoughts. In the presented study, the average level of COVID-19 fear in Turkish society was determined to be $17.4 \pm 5.9$ (7-32). In a study conducted in Western Europe, the average COVID-19 fear level was determined as $17.2 \pm 4.7$ (7-34) (Reznik et al., 2020). These similarities in the level of fear between countries may have been due to the spread of the epidemic, government policies, and level of information given to the public. The epidemic started to spread in these countries around the same time. Being unprepared for the outbreak and lack of 
information on the subject, vague statements of officials, policies on bans may have led to similar results.

The level of fear associated with COVID-19 varies according to various sociodemographic characteristics. In this study, fear scores of females were found to be higher than those of males. In another study conducted in our country, similar to these results, fear of COVID-19 was found higher in females than males (Bakioğlu et al., 2020). In studies conducted in various countries, the level of fear of females was also found to be higher, in line with our study (Reznik et al., 2020) (Tzur Bitan et al., 2020)( Broche-Pérez et al., 2020). The gender difference of COVID-19 fear was consistent with the finding that the coronavirus pandemic caused more psychological effects in females. In addition, females tend to generally have less physical endurance than males (Overfield, 2018); hence, being more prone to getting sick may increase COVID-19 fear. While females express their fears more easily due to their social gender roles, males may not express their fears due to their strong and courageous roles.

In the presented study, the fear level of singles was found to be higher. This situation shows that those who live alone are more afraid of disease and death and that the spouses support each other more in difficult situations. A study conducted in China found that $52.1 \%$ of the participants felt terrified and anxious due to the pandemic, but received great support from friends and family members (Zhang \& Ma, 2020).

While there was no significant correlation between age and COVID-19 fear in this study, occupation, education, and income level affected the fear level. Those with the low education level and tradesmen were less afraid of COVID-19. This suggests that people do not sufficiently understand the seriousness of the COVID-19 pandemic, or that economic concerns are greater enough to ignore conditions such as illness and death. Similarly, a study conducted in Israel determined that participants with low economic levels had higher fear rates than those with high economic income (Tzur Bitan et al., 2020). In another study, it was found that university students and religious individuals had higher levels of fear related to COVID-19 (Reznik et al., 2020). In the present study, no questions were asked about religiosity to the participants. However, there are also studies which could not determine any significant relationship between age, place of residence, education level, and fear (Bakioğlu et al., 2020).

According to the WHOQOL-BREF, those with very good general health and quality of life were found to have low COVID-19 fear score, and those who were not satisfied with life had a high COVID-19 fear score. In a study conducted in health institutions in Vietnam, the quality of life of patients suspected of COVID-19 was found to be lower than those of healthy individuals. The study determined that those with a high health literacy level had better quality of life (Nguyen et al., 2020). Recent studies using the FCV-19S showed that fear of COVID-19 was negatively related to life satisfaction, and this relationship was due to depression, anxiety, and stress (Satici et al., 2020).

In this study, a negative correlation was found the between fear scores, and physical health and psychological health. Each increase of one unit in the physical health field score and psychological health field score resulted in a $19.0 \%$ reduction in COVID-19 fear. As people's fears increase, their psychological and somatic complaints increase and their quality of life decreases. In a study by Harper et al., the physical and environmental quality of life of the participants decreased with increasing COVID-19 fear (Harper et al., 2020). Studies conducted during the pandemic reported a positive correlation between fear level and depression, anxiety, and stress (Ahorsu et al., 2020; Bakioğlu et al., 2020; Soraci et al., 2020). Another study concluded that there was a positive correlation between depression, career anxiety, and COVID-19 fear. (Mahmud 
et al., 2020). During the pandemic, anxiety and depression levels increased along with the health anxiety of individuals ( $\mathrm{Li}$ et al., 2020; Ornell et al., 2020). In addition to health concerns, public health measures (quarantine, isolation, social distance) and job losses and economic problems with the pandemic are likely to have negative effects on psychological health (Alyami et al., 2020; Galea et al., 2020). However, a recent study has shown that fear of COVID-19 increased attention paid to social distancing and hand hygiene, and fear played an important role in complying with public health measures related to COVID-19 (Harper et al., 2020). Fear negatively affected people's daily business life, activities, and social relations.

\section{Limitations, Suggestions, and Conclusion}

As a result, it is important to evaluate the fears. Understanding the level of fear among different groups according to different sociodemographic variables is crucial for establishing necessary education and prevention programs, and determining the target audience. Providing pieces of training to increase general awareness about COVID-19 in society, providing accurate and reliable information through print and visual media, and continuing to share information about the epidemic transparently by the authorities are among the important elements of the fight against fear. In Turkish society, gender, education, and socioeconomic status affected the level of fear, regardless of age. As the level of fear increases, the quality of life decreases, and physical and psychological health changes negatively. In order to get rid of the negative effects created by fear, it can be suggested that society should obtain correct information from reliable sources on the subject, spare enough time for him to stay away from the agenda, and spend quality time by protecting the social distance with his loved ones. People living in different parts of the world have experienced intense fear of COVID-19, despite their geographical and cultural differences (Alyami et al., 2020; Broche-Pérez et al., 2020; Ornell et al., 2020; Ozamiz-Etxebarria et al., 2020; Reznik et al., 2020; Soraci et al., 2020; Tzur Bitan et al., 2020).

The present study has some limitations. First, the study was a cross-sectional study, it was conducted in the early days of the pandemic, and self-report scales were used. The studied participants were from the general Turkish population, and no formal diagnoses on mood disorders were obtained (e.g., anxiety). Also, due to quarantine and curfews, the survey was conducted online survey instead of face-to-face interviews with the participants. Our results cannot be generalized, as the study was conducted with a limited number of participants in a particular community. However, it is recommended that future studies may be a longitudinal study with follow-up periods and take risk factors into consideration with larger numbers of participants.

\section{Declarations}

Ethics Approval All procedures followed were in accordance with the ethical standards of the responsible committee on human experimentation (institutional and national) and with the Helsinki Declaration.

Consent to participate All participants provided electronic informed consent.

Conflict of Interest The authors declare no competing interests. 


\section{References}

Ahorsu, D. K., Lin, C.-Y., Imani, V., Saffari, M., Griffiths, M. D., \& Pakpour, A. H. (2020). The Fear of COVID-19 Scale: Development and initial validation. International Journal of Mental Health and Addiction, 1-9. https://doi.org/10.1007/s11469-020-00270-8.

Alyami, M., Henning, M., Krägeloh, C. U., \& Alyami, H. (2020). Psychometric evaluation of the Arabic version of the Fear of COVID-19 Scale. International Journal of Mental Health and Addiction, 1-14. https://doi.org/10.1007/s11469-020-00316-x.

Bakioğlu, F., Korkmaz, O., \& Ercan, H. (2020). Fear of COVID-19 and positivity: Mediating role of intolerance of uncertainty, depression, anxiety, and stress. International Journal of Mental Health and Addiction. https://doi.org/10.1007/s11469-020-00331-y.

Bavel, J. J. V., Baicker, K., Boggio, P. S., Capraro, V., Cichocka, A., Cikara, M., Crockett, M. J., Crum, A. J., Douglas, K. M., Druckman, J. N., Drury, J., Dube, O., Ellemers, N., Finkel, E. J., Fowler, J. H., Gelfand, M., Han, S., Haslam, S. A., Jetten, J., ... Willer, R. (2020). Using social and behavioural science to support COVID-19 pandemic response. Nature Human Behaviour, 4(5), 460-471. https://doi.org/10. 1038/s41562-020-0884-z.

Broche-Pérez, Y., Fernández-Fleites, Z., Jiménez-Puig, E., Fernández-Castillo, E., \& Rodríguez-Martin, B. C. (2020). Gender and fear of COVID-19 in a Cuban population sample. International journal of mental health and addiction, 1-9. Advance online publication. https://doi.org/10.1007/s11469-020-00343-8.

Eser, E., Fidnner, H., Fidaner, C., Eser, S. Y., Elbi, H., \& Göker, E. (1999). WHOQOL-100 ve WHOQOLBREF' in psikometrik özellikleri. Journal of 3p, 17(2), 24-35.

Galea, S., Merchant, R. M., \& Lurie, N. (2020). The mental health consequences of COVID-19 and physical distancing: The need for prevention and early intervention. JAMA Internal Medicine, 180(6), 817-818. https://doi.org/10.1001/jamainternmed.2020.1562

Harper, C. A., Satchell, L. P., Fido, D., \& Latzman, R. D. (2020). Functional fear predicts public health compliance in the COVID-19 pandemic. International Journal of Mental Health and Addiction, 1-14. https://doi.org/10.1007/s11469-020-00281-5.

Li, J. B., Yang, A., Dou, K., \& Cheung, R. Y. M. (2020). Self-control moderates the association between perceived severity of the coronavirus disease 2019 (COVID-19) and mental health problems among the Chinese public [Preprint]. PsyArXiv. https://doi.org/10.31234/osf.io/2xadq.

Mahmud, Md. S., Talukder, M. U., \& Rahman, Sk. M. (2020). Does 'Fear of COVID-19' trigger future career anxiety? An empirical investigation considering depression from COVID-19 as a mediator. International Journal of Social Psychiatry, 0020764020935488. https://doi.org/10.1177/0020764020 935488.

Nguyen, H. C., Nguyen, M. H., Do, B. N., Tran, C. Q., Nguyen, T. T. P., Pham, K. M., Pham, L. V., Tran, K. V., Duong, T. T., Tran, T. V., Duong, T. H., Nguyen, T. T., Nguyen, Q. H., Hoang, T. M., Nguyen, K. T., Pham, T. T. M., Yang, S.-H., Chao, J.C.-J., \& Duong, T. V. (2020). People with suspected COVID19 symptoms were more likely depressed and had lower health-related quality of life: The potential benefit of health literacy. Journal of Clinical Medicine, 9(4), 965. https://doi.org/10.3390/jcm9040965

Ornell, F., Schuch, J. B., Sordi, A. O., Kessler, F. H. P., Ornell, F., Schuch, J. B., Sordi, A. O., \& Kessler, F. H. P. (2020). "Pandemic fear" and COVID-19: Mental health burden and strategies. Brazilian Journal of Psychiatry, 42(3), 232-235. https://doi.org/10.1590/1516-4446-2020-0008

Overfield, T. (2018). Biological variation in health and illness: Race, age, and sex. CRC Press.

Ozamiz-Etxebarria, N., Dosil-Santamaria, M., Picaza-Gorrochategui, M., \& Idoiaga-Mondragon, N. (2020). Niveles de estrés, ansiedad y depresión en la primera fase del brote del COVID-19 en una muestra recogida en el norte de España. Cadernos De Saúde Pública, 36(4), e00054020. https://doi.org/10.1590/ 0102-311x00054020

Pakpour, A. H., \& Griffiths, M. D. (2020). The fear of COVID-19 and its role in preventive behaviors. Journal of Concurrent Disorders. https://concurrentdisorders.ca/2020/04/03/the-fear-of-covid-19-andits-role-in-preventive-behaviors/.

Reznik, A., Gritsenko, V., Konstantinov, V., Khamenka, N., \& Isralowitz, R. (2020). COVID-19 fear in Eastern Europe: Validation of the Fear of COVID-19 Scale. International Journal of Mental Health and Addiction. https://doi.org/10.1007/s11469-020-00283-3.

Satici, B., Gocet-Tekin, E., Deniz, M. E., \& Satici, S. A. (2020). Adaptation of the Fear of COVID-19 Scale: Its association with psychological distress and life satisfaction in Turkey. International Journal of Mental Health and Addiction, 1-9. https://doi.org/10.1007/s11469-020-00294-0.

Shigemura, J., Ursano, R. J., Morganstein, J. C., Kurosawa, M., \& Benedek, D. M. (2020). Public responses to the novel 2019 coronavirus (2019-nCoV) in Japan: Mental health consequences and target populations. Psychiatry and Clinical Neurosciences, 74(4), 281-282. https://doi.org/10.1111/pcn.12988 
Shultz, J. M., Cooper, J. L., Baingana, F., Oquendo, M. A., Espinel, Z., Althouse, B. M., Marcelin, L. H., Towers, S., Espinola, M., McCoy, C. B., Mazurik, L., Wainberg, M. L., Neria, Y., \& Rechkemmer, A. (2016). The role of fear-related behaviors in the 2013-2016 West Africa ebola virus disease outbreak. Current Psychiatry Reports, 18(11). https://doi.org/10.1007/s11920-016-0741-y.

Soraci, P., Ferrari, A., Abbiati, F. A., Del Fante, E., De Pace, R., Urso, A., \& Griffiths, M. D. (2020). Validation and psychometric evaluation of the Italian version of the Fear of COVID-19 Scale. International Journal of Mental Health and Addiction. https://doi.org/10.1007/s11469-020-00277-1.

TC. Ministry of Health. (2020). COVID-19-New coronavirus diseases [Internet]. Access address: https:// covid19bilgi.saglik.gov.tr/tr/ access date: 17 jul 2020.

The World Health Organization Quality of Life Assessment (WHOQOL): Development and general psychometric properties. (1998). Social Science \& Medicine (1982), 46(12), 1569-1585. https://doi.org/10. 1016/s0277-9536(98)00009-4.

Tzur Bitan, D., Grossman-Giron, A., Bloch, Y., Mayer, Y., Shiffman, N., \& Mendlovic, S. (2020). Fear of COVID-19 scale: Psychometric characteristics, reliability and validity in the Israeli population. Psychiatry Research, 289, 113100. https://doi.org/10.1016/j.psychres.2020.113100

World Health Organization. (2020). Advice for the public on COVID-19 -[Internet]. Access address https:// www.who.int/emergencies/diseases/novel-coronavirus-2019/advice-for-public access date: 16 jul 2020.

Zhang, Y., \& Ma, Z. F. (2020). Impact of the COVID-19 pandemic on mental health and quality of life among local residents in Liaoning Province, China: A cross-sectional study. International Journal of Environmental Research and Public Health, 17(7). https://doi.org/10.3390/ijerph17072381.

Publisher's Note Springer Nature remains neutral with regard to jurisdictional claims in published maps and institutional affiliations. 